\title{
Yapay Sinir Ağları Yardımı ile Yeraltı Suyunda Sodyum Absorbsiyon Oranı (SAR) Tahmini: Ergene Havzası Doğu Akiferi Örneği
}

Prediction of Sodium Absorption Ratio (SAR) in Groundwater with the Aid of Artificial Neural Networks: the East Aquifer of Ergene Basin

\section{Orhan ARKOÇ ${ }^{1}$, Tahir Çetin AKINCI ${ }^{2}$, H. Selçuk NOGAY ${ }^{3}$}

${ }^{1}$ Kırklareli Üniversitesi, Teknik Bilimler Meslek Yüksekokulu, İnşaat Bölümü, KIRKLARELI

${ }^{2}$ İstanbul Teknik Üniversitesi, Elektrik-Elektronik Fakültesi, Elektrik Mühendisliği Bölümü, İSTANBUL

${ }^{3}$ Erciyes Üniversitesi, Mustafa Çıkrıkçıŏ̆lu Yüksekokulu, Elektrik ve Enerji Bölümü, KAYSERI

$\begin{array}{lll}\text { Geliş (received) } & : & 29 \text { Şubat (February) } 2016 \\ \text { Düzeltme (revised) } & : & 20 \text { Nisan (April) } 2016 \\ \text { Kabul (accepted) } & : & 28 \text { Nisan (April) } 2016\end{array}$

ÖZ

Yeraltı suyu dünyanın birçok yerinde içme ve tarımsal sulama amaçlı kullanılmaktadır. Tarımsal faaliyetler zamanla yeraltı sularını kirleterek kalitesinin bozulmasına neden olabilmektedir. Kalitesi bozulmuş bu sular insan sağlığını ve bitkilerin gelişimini olumsuz yönde etkilemektedir. Özellikle kirlenmeye açık serbest akiferlerde yeraltı suyu kalitesinin ucuz yöntemler ile izlenmesi önem kazanmaktadır. $\mathrm{Bu}$ çalışmada Ergene Havzası doğu kesiminde yer alan serbest akiferdeki sodyum absorbsiyon oranı (SAR) değerinin tahmini için bir yapay sinir ağı modeli önerilmektedir. Ergene Havzası doğu kesiminde serbest akiferde açılmış olan 18 su kuyusundan bir yıllık süre ile aylık olarak alınan örneklerden elde edilen elektriksel iletkenlik, toplam çözünmüş katı miktarı, sıcaklık, toplam sertlik, klorür miktarı ve $\mathrm{pH}$ değerleri model için girdi olarak kullanılmıştır. Modellenen yapay sinir ağında, Levenberg-Marquardt (trainlm) geri yayılım algoritması olarak seçilmiş ve 35 nöron sayısı kullanılmıştır. Modelin sonuçları ile hedefler arasında yüksek tutarlılık gözlenmiştir $(\mathrm{R}=0,885)$. Önerilen bu model ile yeraltı sularının daha ucuz ve kolay bir şekilde izlenmesi mümkün olabilecektir.

Anahtar Kelimeler: Ergene Havzası, Sodyum Absorbsiyon Oranı, Yapay Sinir Ağları, Yeraltı Suyu Kalitesi.

\section{ABSTRACT}

Groundwater is used for drinking and irrigation purposes in many parts of the world. Irrigation practices result in the deterioration of the quality of the groundwater over the time and this adversely

O. Arkoç

E-posta: orhan.arkoc@klu.edu.tr 
Arkoç, Akıncı, Nogay

affects the human health and plant growth. Monitoring of the vulnerable aquifers with cost-effective methods is important. In this study an artificial neural network model is proposed for the prediction of sodium absorption ratio (SAR) in the unconfined aquifer, located in the east of Ergene basin. The samples taken from 18 observation wells were analysed monthly for electrical conductivity, total dissolved solids, temperature, total hardness, chloride and $\mathrm{pH}$. Levenberg-Marquardt (trainlm) was selected for backpropagation algorithm and 35 neurons were used in the model architecture. The model follows up the experimental data very closely $(R=0,855)$. Application of the proposed model would make possible to monitor the aquifers in a more cost-effective and easier way.

Keywords: Ergene Basin, Sodium Absorption Ratio, Artificial Neural Networks, Groundwater Quality.

\section{GíRiş}

Ergene Havzası'nın doğu kesimi, İstanbul'a yakınlığı nedeniyle sanayileşmenin etkisi altında kalmıştır. Bununla beraber, arazinin ve toprak yapısının tarıma uygunluğu nedeniyle yoğun tarımsal faaliyet etkisi altındadır (Özkan ve Kubaş, 2008). Bu durum bölgenin yoğun göç almasına ve dolayısı ile nüfus artışına neden olmuştur. $\mathrm{Bu}$ gelişmeler sonucu ortaya çıkan evsel ve endüstriyel atıklar, molozlar, tarımda kullanılan gübre ve ilaçlar muhtemel kirlilik kaynakları olmuştur. Bu kirleticilerden tarımsal kaynaklı olanların neden olduğu kirlilik, en çok gözlenen yayılı kirlilik türüdür. Çeşitli kanserojen pestisitlerin ve gübrelerin kontrolsüz kullanımı, küçük ve büyük ölçekli çeşitli havzalarda yeraltı suyunun kalitesini bozabilmektedir (Bedient vd., 1994).

Bölgede yer alan Çorlu, Çerkezköy, Lüleburgaz ilçeleri yoğun sanayileşme etkisi altında kalmıştır. Özellikle tekstil ve deri işleme sanayii, bölgedeki yeraltı sularını kullanmış, atık sularını Ergene Nehri'ne birakarak nehirdeki kirliliğin artmasına ve suyun sulama amacı ile kullanılamaz hâle gelmesine neden olmuştur. Diğer taraftan bölge, ayçiçeği ve buğday üretiminde önemli bir yere sahiptir. Bölgede tarımsal sulama amaçlı olarak yeraltı suları kullanılmaktadır. Tarımsal arazilerin kontrolsüz ve aşırı sulanması, etkin olmayan drenaj nedeniyle bölgede yer alan serbest akifer kirlenmeye açık durumdadır (Arkoc, 2005). Bu nedenle, bölgedeki serbest akiferler, kirlenmeye karşı koruma amaçlı olarak izlenmelidir.

Sodyum absorbsiyon oranı (SAR) ve elektriksel iletkenlik (EC), tarımsal kullanım amaçlı su kalitesinin belirlenmesinde kullanılan en önemli iki parametredir (Suarez vd., 2006). Yüksek sodyum ve düşük kalsiyum, magnezyum değerleri SAR değerinin yükselmesine sebep olur. SAR, sulama suyundaki sodyumun kalsiyum ve magnezyuma göre bağıl miktarını verir. Yüksek SAR değerine sahip sulama suları toprakta sodyum birikimine sebep olur. Biriken sodyum, bitki tarafından alınır ve belli bir sınır değer aşıldığında bitkinin ozmotik yapısı bozularak suyun dallara ve yapraklara ulaşması engellenir. Bu da verimin düşmesine neden olur. Sulama suyu için SAR değeri aşağıdaki formül yardımı ile hesaplanır (iyon konsantrasyon değerleri meq/L).

$\mathrm{SAR}=[\mathrm{Na}] /(([\mathrm{Ca}]+[\mathrm{Mg}]) / 2)^{1 / 2}$ 
18'den küçük SAR değerlerine sahip sular "iyi” olarak sinıflandırılırken, 26'dan büyük SAR değerlerine sahip sular "kullanılamaz" olarak siniflandirilır (Bauder vd., 2011). Bu nedenle tarımsal faaliyetlerin yoğun olduğu bölgelerde sulama suyu kalitesi açısından akiferlerin izlenmesi önem taşımaktadır. $\mathrm{Bu}$ bağlamda, yeraltı sularındaki SAR değerlerinin uygun maliyetli yöntemler ile izlenmesi ya da tahmin edilmesi önemlidir.

Yapay sinir ağları (YSA) ucuz bir yöntem olarak; finans, enerji, tıp, ekoloji gibi disiplinlerde tahmin amaçlı güçlü bir araç olarak kullanılmıştır (Karayiannis ve Venetsanopoulos, 2013). Öğrenme kabiliyeti, sistem değişikliklerine karşı davranışını düzenlemesi, donanımın kolay kurulabilmesi gibi özellikleri, YSA ile elde edilen çözümleri çeşitlendirmektedir. YSA kullanılarak, suda tuzluluk tahmini (Maier ve Dandy, 1996), atık suda günlük askıdaki sediment miktarı (Cığızoğlu, 2004), atık kokusu ve biyolojik oksijen ihtiyacı arasındaki ilişki (Onkal-Engin vd., 2005), yeraltı sularina nitrat ve SAR tahmini (Yeşilnacar vd., 2008; Yeşilnacar ve Şahinkaya, 2012), Quebec, Kanada yeraltı su seviyesi tahmini (Adamowski vd., 2011), Mardin (Türkiye) kısa dönem rüzgar hızı tahmini (Nogay vd., 2012), İran Chalgazi nehri SAR miktarı (Asadollahfardi vd., 2013) ve akarsu su kalite tahmini (Sengorur vd., 2015) gibi çalışmalar yapılmıştır.

$\mathrm{Bu}$ çalışmada Ergene Havzası doğu kesimindeki 18 su kuyusundan alınan örnekler üzerinde yapılan çalışma ile, YSA kullanılarak, sulama amacıyla kullanılan yeraltı sularındaki SAR değerleri tahmin edilmeye çalışılmıştır.

\section{ÇALIŞMA ALANI}

Çalışma alanı Türkiye'nin Kuzeybatısı'nda, Trakya Bölgesi'nde, Kırklareli ve Tekirdağ il sınırları içinde yer almaktadır. Çalışma alanının kuzey kesimi daha yüksek ve nispeten tepelik iken orta ve güney kesimleri düşük eğimli vadiler ve düzlüklerden oluşmaktadır. Bölgede yer alan Çorlu Deresi ve Ergene Nehri'nin kuzey drenaj alanı çalışma sahasını oluşturur.

Çalışma alanında karasal iklim hakimdir. Uzun y1llar yağış ortalaması $509.6 \mathrm{~mm}$ iken, en soğuk aylar Ocak ve Şubat, en sicak aylar ise Temmuz ve Ağustos'tur. Uzun y1llar sicaklık ortalamas1 (1966-2004) 12.1 C'dir. Çalışma, Mayıs 2003 ile Nisan 2004 arasında, 18 su kuyusundan her ay alınan numunelerle yapılmıştır. Çalışma alanının büyük bir kesiminde gözlenen Ergene Formasyonu ve Trakya Formasyonu akifer potansiyeli yönünden önemlidirler. Özellikle Ergene Formasyonu, üst kesimlere doğru incelen tane boyu ile belirgin bir litoloji sunar. Yeraltı suyu taşıyan kesimler, siltli kum, kumtaşı, çakıltaşı seviyeleridir. Tüm su kuyuları bölgedeki serbest akifer olan Miyosen yaşlı Ergene Formasyonu'ndan su almaktadır. Bölgenin detaylı jeolojisi ve hidrojeolojisi literatürde yer almaktadır (Arkoç, 2005; Arkoç ve Erdoğan, 2011). 


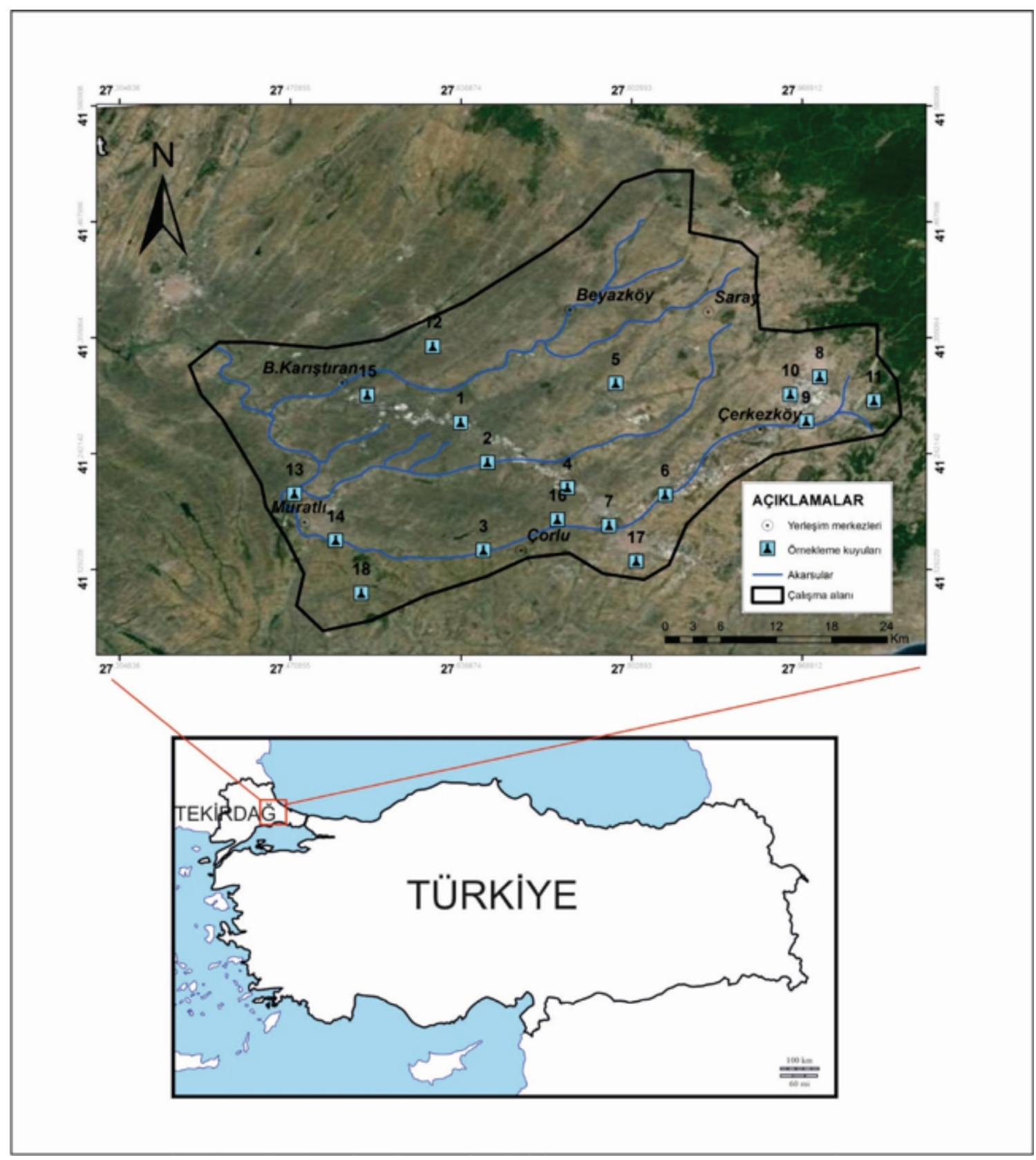

Şekil 1. Çalışma alanının yerbulduru haritası ve su kuyularının lokasyonları.

Figure 1. Location map of the study area and the location of sampling wells. 


\section{ANALITIKK YÖNTEMLER}

Yeraltı sularından alınan örneklerdeki elektriksel iletkenlik (EC), toplam çözünmüş katı (TDS), sıcaklık (T) ve pH ölçümleri, filtre edilmemiş örneklerde Hanna HI 98312 portatif test cihazı ve Toledo Mettler $\mathrm{pH}$ metre ile arazide yapılmıştır. $\mathrm{Ca}^{2+}, \mathrm{Mg}^{2+}$ konsantrasyonları Nitrik asit ile korunmuş örneklerde atomik absorpsiyon spektrofotometresi (Unicam AS969) ile, $\mathrm{Cl}^{-}$konsantrasyonları ise volumetrik olarak (Schimadzu UV1650) hesaplanmıştır.

Toplam sertlik hesaplamasında aşağıdaki formül kullanılmıştır (tüm birimler $\mathrm{mg} / \mathrm{L})$ :

$\mathrm{TH}\left(\mathrm{CaCO}_{3} / \mathrm{L}\right)=2,5 *\left[\mathrm{Ca}^{2+}\right]+4,1 *\left[\mathrm{Mg}^{2+}\right]$

\section{MODELLEME}

Yapay sinir ağları (YSA) insan beyninin çalışma sisteminden esinlenerek ortaya çıkmıştır. YSA insan beynindeki birçok nöronun, birbirlerine değişik etki seviyeleri ile bağlanması sonucu oluşan karmaşık bir sistem olarak düşünülebilir. Başlangıçta insan beynindeki nöronların matematiksel olarak modellenmesi amacıyla başlayan çalışmalar, günümüzde belirli bir disiplin haline gelmiş, birçok farklı bilimsel alanda araştırma konusu olmuştur. YSA genelde çok farklı yapıda ve formlarda bulunabilen enformasyon verilerinin çok hızlı bir şekilde tanımlanarak algılanması esasına dayanır. YSA, veriler arasındaki bilinmeyen ve fark edilmesi güç ilişkileri ortaya çıkartabilir. Girdi ve çıktı değişkenleri arasındaki herhangi bir ön bilgiye ihtiyaç duymadan, herhangi bir varsayımda bulunmadan, doğrusal olmayan modellemeyi sağlayabilmektedir (Kaastra ve Boyd, 1996).
Ağa, girdi bilgileri ve bu girdilere karşıllık gelen çıktı bilgileri verilmekte ve ağın girdiçıktı arasındaki ilişkiyi öğrenmesi sağlanmakta, böylece ağın eğitimi gerçekleştirilmektedir. Öğreticili öğrenme olarak adlandırılan bu yöntem genelde tercih edilen bir yöntemdir (Peng vd., 1992). Öğreticili öğrenme yöntemi ile eğitilen ağ yapıları (geriye yayılım yapay sinir ağları ve radyal tabanlı yapay sinir ağları), mevcut problemlerin çözümünde kullanılmaktadır.

YSA, öngörülen sayıda yapay sinir hücresinin, veri işlemek amacıyla belirli bir mimari ile yapılandırılmasıyla ortaya çıkar. $\mathrm{Bu}$ mimari yapı, numaralandirılan birkaç katmandan oluşmaktadır. İlk katman, çoğunlukla numaralandırılmayan, giriş katmanıdır. $\mathrm{Bu}$ katman, giriş katmanındaki elemanların ağırlık çarpanları ve aktivasyon fonksiyonlarının olmaması nedeniyle numaralandırılmaz. Diğer ara katmanların sayısı değişebilmektedir ve gizli katman ismi ile anılır. Çoğu zaman tek gizli katmanın uygun olacağı belirtilmekle beraber (El-Din ve Smith, 2002), birden fazla gizli katman kullanılarak geniş çapta hedef fonksiyonu uyarlanabilmektedir (Toth vd., 2000). Son katman ise çıkış katmanı olarak adlandırılır. Analizlerde, geriye yayılım yapay sinir ağı modeli (GYYSAM) çok tercih edilen, çok katmanlı bir tahmin modelidir.

Şekil 2'de, çalışmada kullanılan YSA modeli gösterilmektedir. GYYSAM ile yapılan çalışmada; giriş katmanı, gizli katman ve çıkış katmanı olmak üzere üç katman kullanılmıştır. Giriş katmanında pH, EC, TDS, Cl, TH, T olmak üzere altı giriş vardır. Gizli katmanda, YSA modelinin ortalama davranışı öğrenmesi istendiği için, nöron geçiş fonksiyonu olarak sigmoid transfer fonksiyonu seçilmiştir. Çıkış 
katmanında ise lineer transfer fonksiyonu kullanılmıştır. Çalışmada üç grup veri seti kullanılmıştır. $\mathrm{Bu}$ verilerin toplam sayısı 203 olup, 20 tanesi doğrulama, 30 tanesi test, kalan 153 tanesi ise YSA'yı eğitmek için kullanılmıştır.

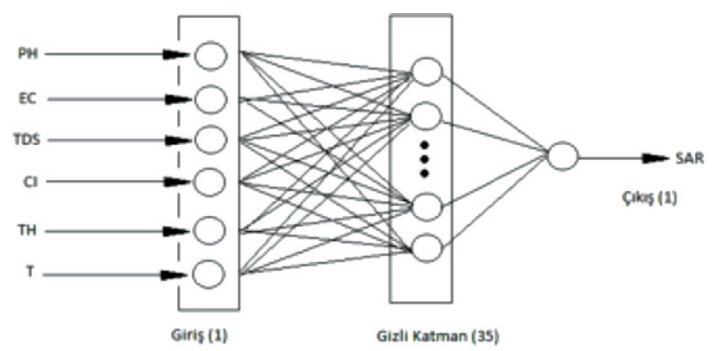

Şekil 2. Gözlem kuyularından SAR tahmini için geliştirilen sinir ağı modeli.

Figure 2. The neural network structure for the prediction of SAR in the monitoring wells.

\section{GERIYY YAYILIM ALGORITMASI SEÇIMI}

Geriye yayılım yapay sinir ağ1 modeli (GYYSAM), sıklıkla kullanılan bir a ă yapısıdır. Standart geri yayılım algoritması, ağ ağılıklarının, performans fonksiyonunun negatif gradyanı yönünde ilerlediği gradyan iniş algoritmasıdır. Bir çok çeşidi olan geri yayılım algoritması, gradyan iniş ve newton metodu gibi standart optimizasyon tekniklerine dayanmaktadır ve yapay sinir ağları içerisinde her probleme uyarlanabilir (Lipmann, 1987). Geriye yayılım modeli geri beslemeli bir öğrenme mekanizması kullanır. Yapay sinir ağının yapısı ileri beslemeli olmasına rağmen, hatanın geriye doğru ket vurmasından kaynaklanan bir öğrenme olduğu için, geri besleme öğrenmede önemli bir etken haline gelmektedir. Bu tip öğrenme algoritması, sürekli girdi tipini kullanır. $\mathrm{Bu}$ çalışmada, literatürde çok sık kullanılan Levenberg-Marquardt (trainlm) öğrenme algoritması seçilmiştir.

Öğrenme algoritmasının seçiminden sonra gizli katmandaki nöron sayısının belirlenmesi gerekir. Bir katmanda kullanılacak nöron sayısı olabildiğince az olmalıdır. Nöron sayısının az olması yapay sinir ağının «genelleme» yeteneğini arttırırken, gereğinden fazla olması ağın verileri ezberlemesine neden olur. Ancak gereğinden az nöron kullanılması, verilerdeki örüntünün ağ tarafından öğrenilememesi gibi bir sorun yaratabilir (Stern, 1996). Bu çalışmada, gizli katmandaki nöron sayısı, YSA öğrenme performansı için kullanılan karesel ortalama hata (MSE) değerinin anlamlı bir değişim göstermemeye başladığı nöron sayısı olan otuzbeş olarak seçilmiştir. Çıkış katmanında ise tek çıkış olan SAR tahmini vardır.

\section{TARTIŞMALAR}

SAR, pH, EC, TDS, Cl, TH ve T arasındaki ilişkinin tanımlanması için hesaplanan korelasyon katsayıları oldukça düşüktür (Çizelge 1). SAR değeri ile en yüksek korelasyon, EC değeri ile olan $R=0.674$ 'tür. Benzer şekilde, SAR bağımlı değişken ve pH, EC TDS, Cl, TH ve $\mathrm{T}$ bağımsız değişken olarak yapılan lineer regresyon analizinde de $R^{2}$ değerleri 0.45 olarak hesaplanmıştır. 
Çizelge 1. YSA modellemesinde kullanılan parametreler arasındaki korelasyon katsayıları (R).

Table 1. Correlation coefficients (R) among parameters used for the ANN modelling.

\begin{tabular}{|c|c|c|c|c|c|c|c|}
\hline & $\mathrm{pH}$ & $\mathrm{EC}$ & TDS & $\mathrm{Cl}$ & $\mathrm{TH}$ & $\mathrm{T}($ Sicaklık) & SAR \\
\hline $\mathrm{pH}$ & 1 & & & & & & \\
\hline $\mathrm{EC}$ & -.137 & 1 & & & & & \\
\hline TDS & $-.141 *$ & $.998 * *$ & 1 & & & & \\
\hline $\mathrm{Cl}$ & $-.182 * *$ & $.637 * *$ & $.628 * *$ & 1 & & & \\
\hline $\mathrm{TH}$ & $-.139 *$ & $.756^{* *}$ & $.754 * *$ & $.552 * *$ & 1 & & \\
\hline $\mathrm{T}$ (S1cakl1k) & $.197 * *$ & $-.335^{* *}$ & $-.332 * *$ & $-.534 * *$ & $-.309 * *$ & 1 & \\
\hline SAR & -.127 & $.674 * *$ & $.670 * *$ & $.571^{* *}$ & $.522 * *$ & $-.439 * *$ & 1 \\
\hline
\end{tabular}

*. Korelasyon 0.05 seviyesinde anlamlıdır. .

**. Korelasyon 0.01 seviyesinde anlamlıdir.

Görüldüğü gibi girdi olarak kullanılan veriler ile çıtı olarak elde edilen SAR verileri arasındaki ilişki oldukça zayıftır. $\mathrm{Bu}$ nedenle, YSA gibi daha kuvvetli ilişki kurabilen yöntemlere ihtiyaç duyulmaktadır (Mjalli vd., 2007). Bu bağlamda Ergene havzası doğu kesimi serbest akiferinden su alan 18 kuyudan alınan örnekler ile, YSA yöntemi kullanılarak SAR tahmininin yapılabilirliği araştırılmıştır. Ergene Havzası doğu kesiminin su kalitesi hakkında literatürde çalışmalar bulunmaktadır (Kaykığlu ve Ekmekyapar, 2005; Güneş vd., 2008; Arkoç, 2011, 2014).

Girdi olarak kullanılan inceleme alanındaki parametrelerin değişimleri şekil 3'te verilmiştir. Çalışma alanındaki yeraltı sularının pH değerleri 7.8ile5.9 arasındadeğişimgöstermekteolup, genel olarak alkalidir. Suların elektriksel iletkenlikleri ise 315 ile $1347 \mu \mathrm{S} / \mathrm{cm}$ arasında olup ortalama $665 \mu \mathrm{S} / \mathrm{cm}$ 'dir. Elektriksel iletkenlik için, TS266 ve Avrupa Birliği tarafından izin verilen maksimum değer olan $2500 \mu \mathrm{S} / \mathrm{cm}$ 'yi hiçbir örnek geçmemektedir. Yeraltı su örneklerindeki toplam çözünmüş katı miktarı 708.94 ile 165.78 $\mathrm{mg} / \mathrm{l}$ arasında değişmektedir. $\mathrm{Bu}$ değerler dünya sağlık örgütü tarafından kabul edilebilir sinırlardadır (WHO, 2006). Klorür değerleri ise 7.2 ile $97.7 \mathrm{mg} / 1$ arasinda olup ortalama 24.1 $\mathrm{mg} / \mathrm{l}$ ' dir. Bu değerler TS266 sınır değerinin (250 mg/l) oldukça altındadır. 18 gözlem kuyusundaki toplam sertlik değerleri ise 552.7 ile $113.8 \mathrm{mg}$ $\mathrm{CaCO}_{3} / \mathrm{L}$ arasında değişmektedir. Kuyulardaki su sıcaklığı ise ortalama $19.9 \mathrm{C}^{\circ}$ civarındadır. Yeraltı sularındaki SAR oranları 0.06 ile 1.75 arasında değişmekte olup ortalama 0.61 dir. $\mathrm{Bu}$ değerler izin verilen maksimum sinır değer olan 26 'nın altında kalmaktadır. 

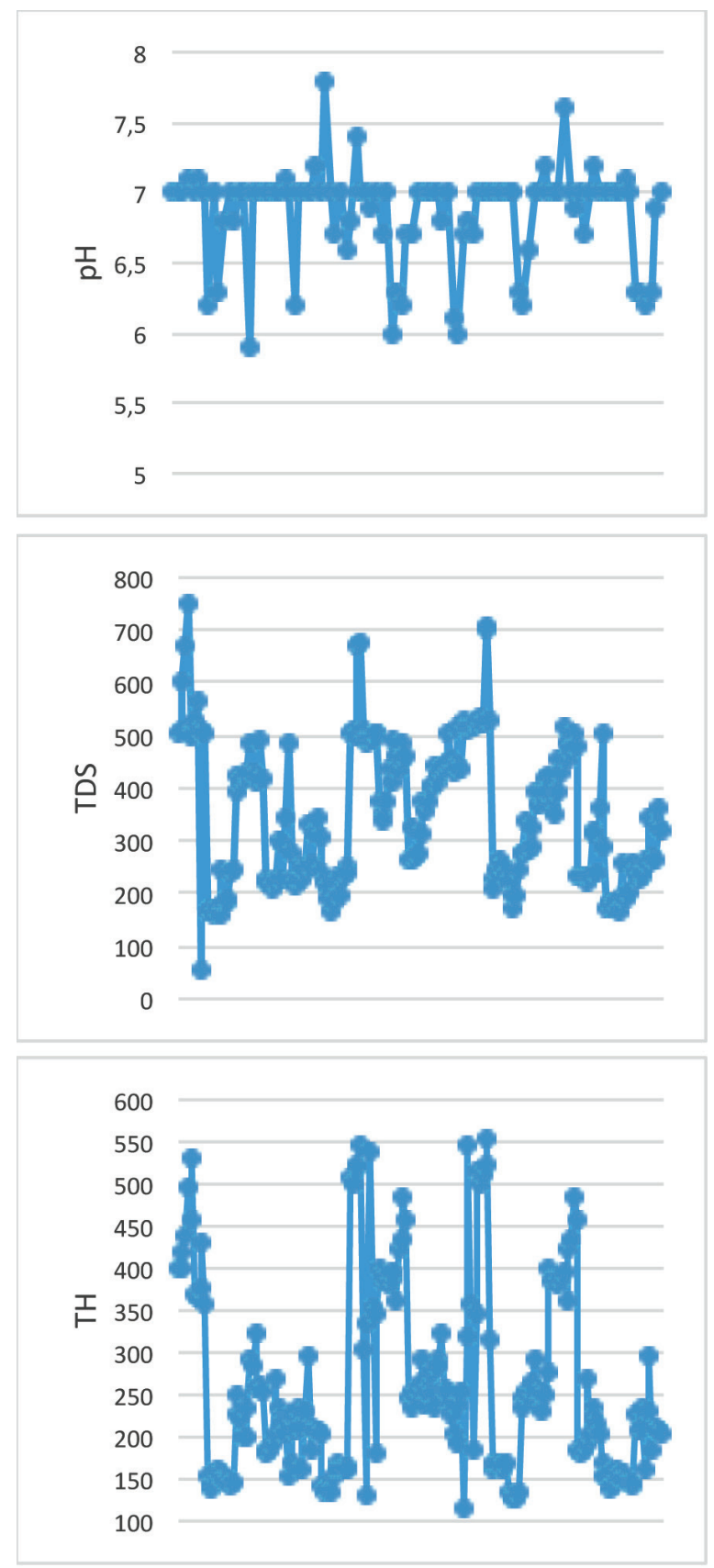

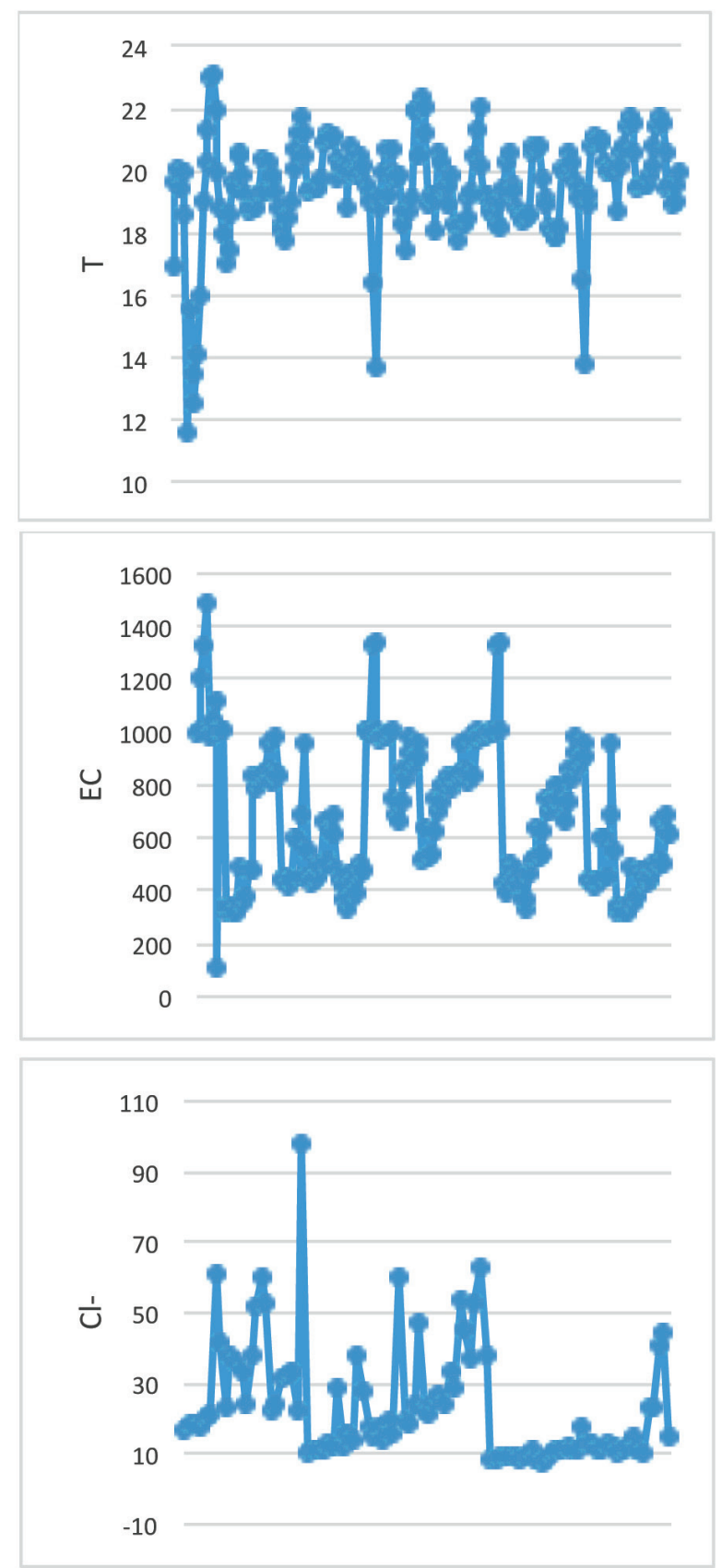

Şekil 3. YSA modellemesinde kullanılan parametrelerin tüm gözlem kuyularında değişimi.

Figure 3. The variation of input parameters in the ANN modeling. 
Şekil 4'ten de anlaşılacağı üzere, 14 güncellenme sayısında (adım, epoch) MSE değerlerinin değişmediği gözlemlenmiş ve öğrenme sonlandırılmıştır. En iyi doğrulama performansının oluştuğu 8 . iterasyona kadar dikkate değer ezberleme belirtisi görülmemektedir çünkü, bu iterasyondan itibaren doğrulama ve test setinde hata oranı artmamaktadır. Doğrulama seti hatası ve test seti hatası benzer karakter gösterdiğinden ve önemli bir ezberleme oluşmadığından, ağın performans1 kabul edilebilir seviyededir. $R$ korelasyon katsayısı, çıktılardaki varyasyonun hedefler tarafından ne kadar iyi açıklandığının bir ölçüsüdür. $R$ değerinin 1'e yaklaşması ilişskinin güçlendiğini, 0'a yaklaşması zayıfladığını ifade etmektedir (Kalayc1, 2010). YSA tarafindan üretilen sonuç ile hedeflenen sonuç arasındaki ilişki şekil 5'te verilmiştir. Hesaplanan sonuç ve hedeflenen sonuç arasındaki $R$ ve MSE değerleri siras1 ile 0.885 ve 0.051 olarak bulunmuștur. YSA tarafından üretilen ve gözlemlenen değerler arasındaki değişim şekil 6'da verilmiştir. Şekil 6 incelendiğinde, hedeflenen ve üretilen çıkış değerleri eğrilerinin birbiri ile uyumlu olduğu görülmektedir. Bu sonuçlar YSA'nın SAR tahmininde güçlü bir araç olduğunu göstermektedir.

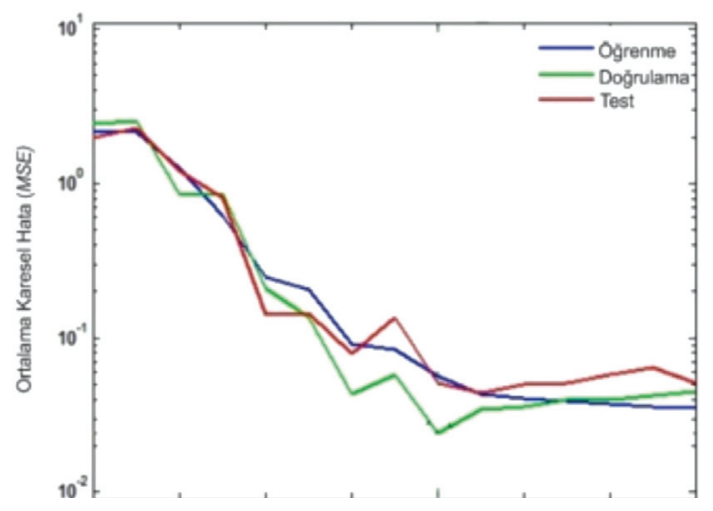

Şekil 4. Levenberg-Marquardt algoritması kullanılarak 35 nöron ile yapılan SAR tahmininde öğrenme, doğrulama ve test ortalama karesel hataları.

Figure 4. Training, validation and test square mean errors for the SAR prediction using LevenbergMarquardt algorithm with 35 neurons.

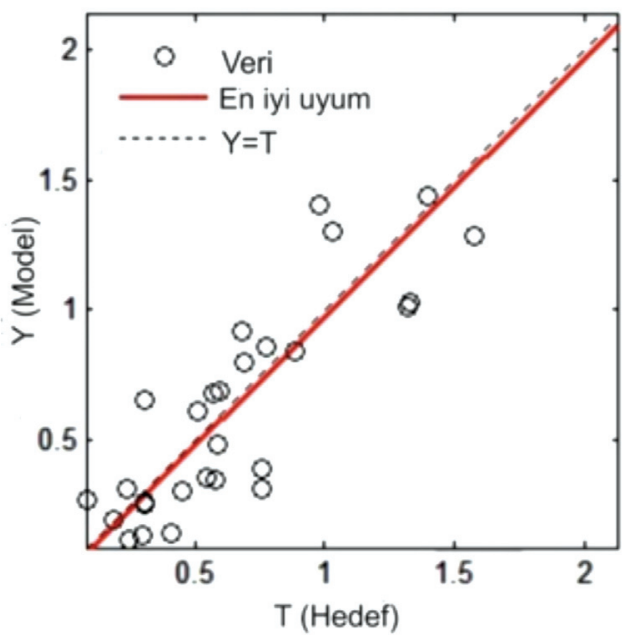

Şekil 5. SAR tahmini için 35 nöron sayısı ile Levenberg-Marquardt algoritması kullanılarak elde edilen YSA sonuçları (Y) ile hedefler (T) arasındaki doğrusal regresyon grafiği.

Figure 5. Linear regression between the ANN outputs $(Y)$ and the corresponding targets $(T)$ using algorithm with 35 neurons for SAR. 


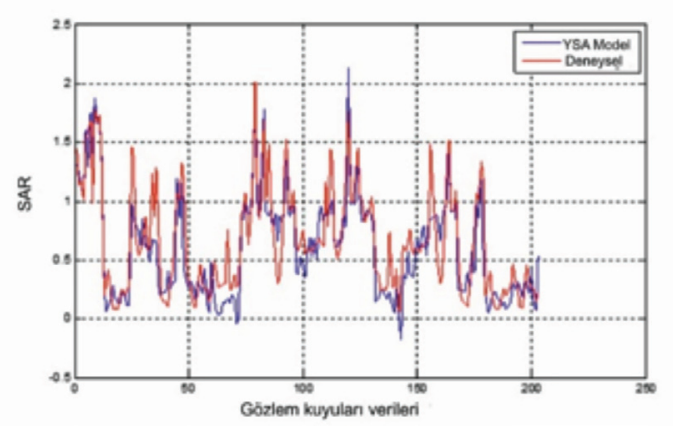

Şekil 6. Ölçülen ve YSA ile tahmin edilen SAR değerleri.

Figure 6. Measured and predicted neural network values of SAR.

YSA modellemesinde kullanilan her bir parametrenin çıkarılmasının, YSA performansına olan etkisi, (Gontarski vd., 2000) tarafindan önerilen aşağıdaki formülle, $R$ değerleri kullanılarak analiz edilmiştir.

$$
(\% \text { etki })=100\left(1-R_{i} / R_{C B}\right)
$$

$\mathrm{Bu}$ formülde; $R_{\mathrm{CB}}$, tahmin edilen ve gözlenen değerler arasındaki temel korelasyon katsayısını, $R_{\mathrm{I}}$ ise, her bir girdinin ihmal edilesi sonucu elde edilen korelasyon katsayısını ifade etmektedir. SAR değeri tahmini için yapılan modellemede en yüksek etki EC değerinin çıkarılması ile gerçekleşmiş, $R$ değeri \% 15.81 azalmıştır (çizelge 2). Benzer şekilde TDS değerinin çıkarılması $R$ değerinde \% 14.23 azalmaya neden olmuştur. $\mathrm{Bu}$ durum EC ile TDS değerleri arasında birçok su için TDS $=0.65^{*} \mathrm{EC}$ şeklinde doğrudan korelasyon olması ile açıklanabilir. $\mathrm{Bu}$ çalışmada YSA'nın kalibrasyonunda kullanılan en yüksek SAR değeri 2 olup izin verilen sınır değer ise 26'dır.
Çizelge 2. Her bir değişkenin YSA tahmin performansına olan etkisi.

Table 2. Influnce of each variable on the performance of ANN prediction.

\begin{tabular}{ccc}
\hline Değişken & $R$ & $\begin{array}{c}R \text { üzerinde } \% \\
\text { etkisi }\end{array}$ \\
\hline Temel durum & 0.885 & - \\
$\mathrm{pH}$ & 0.878 & 0.79 \\
$\mathrm{EC}$ & 0.745 & 15.81 \\
$\mathrm{TDS}$ & 0.759 & 14.23 \\
$\mathrm{Cl}$ & 0.810 & 8.47 \\
$\mathrm{TH}$ & 0.867 & 2.03 \\
$\mathrm{~T}$ & 0.850 & 3.95 \\
\hline
\end{tabular}

Ancak YSA'nın mimarisi tüm değerlere uygun cevap verecek şekilde tasarlandığı için, tasarımı yapılan bu model ile, yeraltı sularındaki sınır değerin üzerinde olan SAR değerleri de tahmin edilebilecektir. $\mathrm{Bu}$ şekilde, yeraltı suyu işletmesindeki büyük miktarda verinin değerlendirilmesi kolaylaşmış olacaktır.

\section{SONUÇLAR VE ÖNERİLER}

$\mathrm{Bu}$ çalışma, Ergene Havzası'nda açılan 18 adet gözlem kuyusundaki SAR değerlerinin tahmininde, Yapay Sinir Ağları'nın (YSA) güvenilir bir araç olduğunu göstermiştir. Yeraltı sularındaki SAR değeri aşırı sulama ve gübre kullanımı ile artış gösterebilmektedir. Tasarımı yapılan, test edilip, hedeflenen sonuçları verdiği gözlenen YSA modeli ile, çalışma alanındaki SAR değerleri kolaylıkla tahmin edilebilmiştir. SAR tahminde en etkin parametrelerin EC ve TDS olduğu gözlenmiştir. Bunun nedeni, iki parametre arasında doğrudan bir korelasyon olmasıdır. Bu nedenle TDS gibi ölçülmesi zor ve pahalı bir parametre yerine sadece EC değerinin kullanılması daha uygun olacaktır. 
Uygulanan modelin geniş ölçekli veriye iyi uyum sağlaması, modelin diğer sahalar için optimize edilmesi ile uygulanabilirliğini daha da kolaylaşacaktır. Bu çalışmada, sensör teknolojisi yardımı ile ölçülebilen parametreler ile beraber rutin su kalitesi analiz parametreleri kullanılmıştır. Daha sonraki çalışmalarda, YSA modelinin tasarlanması sirasında kullanılan parametrelerin seçimi ve birbirleri ile olan etkileşimlerinin ayrıca araştırılması, modelin tutarlılığını artıracaktır. Özellikle nispeten ucuz bir yöntem olan sensör teknolojisi ile ölçümü yapılabilen parametrelerin seçilmesi, çalışmanın daha da ekonomik olmasını sağlayacaktır. Tasarımı yapılan bu model ile, yeraltı sularının izlenmesi ve işletilmesi daha ucuz ve kolay bir şekilde yapılabilecektir.

\section{KATKI BELIRTME}

Yazarlar, değerli görüşleri ve bilgileri ile katkıda bulunan hakemlere çok teşekkür eder.

\section{KAYNAKLAR}

Adamowski, J., Fung Chan, H., Prasher, S. O., Ozga Zielinski, B., Sliusarieva, A., 2012. Comparison of multiple linear and nonlinear regression, autoregressive integrated moving average, artificial neural network, and wavelet artificial neural network methods for urban water demand forecasting in Montreal, Canada. Water Resources Research, 48 (1),1-14.

Arkoç, O., 2005. Ergene Havzası Çorlu-Çerkezköy arasındaki kesiminin hidrojeolojisi. İstanbul Teknik Üniversitesi Fen Bilimleri Enstitüsü, İstanbul, Doktora Tezi, 144 s (yayımlanmamış).

Arkoç, O., 2011. Assessment of water quality of east part of the Ergene basin, Turkey. Journal of
Environmental Protection and Ecology, 12 (4), 1644-1655.

Arkoç, O., Erdoğan, M., 2011. Ergene Havzas1, Çorlu-Çerkezköy arasındaki kesiminin hidrojeokimyası. İTÜ Dergisi/d, 5 (2), 125-134.

Arkoç, O., 2014. Municipal solid waste landfill site selection using geographical information systems: a case study from Çorlu, Turkey. Arabian Journal of Geosciences, 7 (11), 49754985.

Asadollahfardi, G., Hemati, A., Moradinejad, S., Asadollahfardi, R., 2013. Sodium adsorption ratio (SAR) prediction of the Chalghazi river using artificial neural network (ANN) Iran. Current World Environment, 8 (2), 169-178.

Bauder, T. A., Waskom, R. M., Davis, J. G., Sutherland, P. L., 2011. Colorado State University Extension, Report for Irrigation water quality criteria, no.0.506, 4s. Fort Collins, CO, USA.

Bedient, P. B., Rifai, H. S., Newell, C. J., 1994. Ground water contamination: transport and remediation. Prentice Hall, Englewood Cliffs, 540 p.

Cığızoğlu, H. K., 2004. Estimation and forecasting of daily suspended sediment data by multi layer perceptrons, Advances in Water Resources, 27, 185-195.

El-Din, A. G., Smith, D. W., 2002. A neural network model to predict the wastewater inflow incorporating rainfall events. Water Research, 36 (5),1115-1126.

Gontarski, C. A., Rodrigues, P. R., Mori, M., Prenem, L. F., 2000. Simulation of an industrial wastewater treatment plant using artificial neural networks. Computers \& Chemical Engineering, 24 (2), 1719-1723.

Journal of Geological Engineering 40 (2) 2016 
Güneş, E. H., Güneş, Y., Talınıe, I., 2008. Toxicity evaluation of industrial and land base sources in a river basin. Desalination, 226 (1), 348-356.

Kaastra, I., Boyd, M., 1996. Designing a neural network for forecasting financial and economic time series. Neurocomputing, 10, 215-236.

Kalaycı, S., 2010. SPSS Uygulamalı Çok Değişkenli İstatistik Teknikleri. Asil Yayınları, Ankara, 426s. .

Karayiannis, N., Venetsanopoulos, A. N., 2013. Artificial Neural Networks: Learning Algorithms, Performance Evaluation, and Applications. Springer Science \& Business Media, No: 209, $373 \mathrm{p}$.

Kaykığlu, G., Ekmekyapar, F., 2005. Ergene Havzası'nda endüstriyel işlem suyu olarak kullanılan yeraltı sularının özellikleri üzerine bir araştırma. Trakya University Journal of Natural Sciences, 6 (1), 85-91.

Lippmann, R. P., 1987. An introduction to computing with neural nets. ASSP Magazine, IEEE, 4 (2), 4-22.

Maier, H. R., Dandy, G. C., 1996. The use of artificial neural networks for the prediction of water quality parameters. Water Resources Research, 32 (4), 1013-1022.

Mjalli, F. S., Al-Asheh, S., Alfadala, H. E., 2007. Use of artificial neural network black-box modeling for the prediction of wastewater treatment plants performance. Journal of Environmental Management, 83 (3), 329-338.

Nogay, H. S., Akinci, T. C., Eidukeviciute, M., 2012. Application of artificial neural networks for short term wind speed forecasting in Mardin, Turkey. Journal of Energy in Southern Africa, 23 (4), 3.

Onkal-Engin, G., Demir, I., Engin, S. N., 2005. Determination of the relationship between sewage odour and BOD by neural networks.
Environmental Modelling Software 20 (7), 843850.

Özkan, E., Kubaş, A., 2008. Ergene havzasında kirliliğin sosyo ekonomik etkileri. Havza kirliliği konferans1, İzmir, 1, 15-21.

Peng, T. M., Hubele, N. F., Karady, G. G., 1992. Advancement in the application of neural networks for STLF. IEEE Transactions on Power Systems, 7 (1), 250-257.

Şengörür, B., Köklü, R., Ateş, A., 2015. Water quality assessment using artificial intelligence techniques: SOM and ANN-A case study of Melen River Turkey. Water Quality, Exposure and Health, 7 (4), 469-490.

Stern, H. S., 1996. Neural networks in applied statistics. Technometrics, 38 (3), 205-214.

Suarez, D. L., Wood, J. D., Lesch, S. M., 2006. Effect of SAR on water infiltration under a sequential rain-irrigation management system. Agricultural Water Management, 86 (1), 150-164.

Toth, E., Brath, A., Montanari, A., 2000. Comparison of short-term rainfall prediction models for realtime flood forecasting. Journal of Hydrology, 239 (1-4), 132-147.

WHO, 2006. A compendium of drinking-water quality standards in the eastern Mediterranean region. World Health Organization, Geneva, Document No. WHO-EM/CEH/143/E.

Yeşilnacar, M. I., Şahinkaya, E., 2012. Artificial neural network prediction of sulfate and SAR in an unconfined aquifer in southeastern Turkey. Environmental Earth Sciences, 67 (4), 11111119.

Yeşilnacar, M. I., Şahinkaya, E., Naz, M., Özkaya, B., 2008. Neural network prediction of nitrate in groundwater of Harran Plain, Turkey. Environmental Geology, 56 (1), 19-25. 